\title{
PREVENTION OF BLOOD-BORNE INFECTIONS AMONG NURSES AT DR. IVAN SELIMINSKI HOSPITAL, SLIVEN
}

\author{
Pepa Dzhedzheva, Elena Zheleva, Ivan Alexandrov, Ivan Dimitrov \\ Medical University of Varna, Sliven Affiliate
}

\begin{abstract}
INTRODUCTION: The occupational activities of nurses entail a daily exposure to infectious and non-infectious factors that can affect their health. Blood-transmitted pathogens caused by occupational exposure pose the most serious threat. Prevention strategies include vaccinations and universal precaution measures.

AIM: The aim of this study is to assess vaccinations and other precautionary measures against blood-borne infections: HBV, HCV, HIV, and the attitude towards those among nurses at Dr. Ivan Seliminski Hospital, Sliven.

MATERIALS AND METHODS: We used an individual anonymous survey among 55 nurses working in different wards of the Hospital.

RESULTS AND CONCLUSION: A large number of nurses at the hospital have had an HBV immunisation (69\%). A significant proportion have also had serologic status testing for HCV and HIV (58\%). Most nurses indicated they have had immunisation and testing as a precautionary measure.
\end{abstract}

Keywords: blood-borne infections, vaccination, prevention, nurse

\section{INTRODUCTION}

Social Significance of the Problem

The occupational activities of nurses entail a daily exposure to infectious and non-infectious factors that can affect their health.

In particular, a common problem amongst nurses are in-hospital infections caused by bloodborne pathogens - HBV, HCV, and HIV. Given the significant spread of such diseases amongst the population, the number of infected patients in medical establishments is also high.

Address for correspondence:

Pepa Dzhedzheva

Faculty of Public Health

Sliven Affiliate

Medical University of Varna

30 General Stoletov St

Sliven

e-mail: p.djedjeva@gmail.com

\section{Primary Prevention}

The key factor enabling real protection of the medical personnel are vaccinations and personal protective equipment. In 1988, Bulgaria introduced the use of a recombinant HBV vaccine among risk groups. In 1992, the recombinant HBV vaccine was also included as a mandatory vaccination for children in the National Immunisation Calendar to manage the disease. The following groups also received the vaccination: healthcare professionals and staff in medical and healthcare institutions, carriers of HIV, police and army staff, haemodialysis patients, liver disease patients, as well as carriers of HCV and contacts of carriers of HBV, injection drug users, people with an increased risk in relation to sexual behaviour, and people travelling to countries with a high prevalence of HBV.

In order to limit the disease, it is critical to establish adequate healthcare policy, aimed at vaccine prophylaxis, providing effective screening and access to timely treatment (1). 
Pepa Dzhedzheva, Elena Zheleva, Ivan Alexandrov et al.

\section{Review of Conducted Research on the Issue}

Data from the conducted research shows that the risk of an HBV infection among nurses is higher relative to the risk among the general public, so HBV vaccination is highly recommended for those working in healthcare $(9,10)$.

According to papers and recommendations of the Centres of Disease Control and Prevention (CDC), heads of healthcare institutions often disregard the need to vaccinate staff due to financial restraints, and some would only hire nurses if they themselves take responsibility for their own vaccination (16).

The number of healthcare staff vaccinated against $\mathrm{HBV}$ is $67 \%$ in North America, $71 \%$ in Europe, $77 \%$ in the West Pacific region, and $18 \%$ in Southeast Asia (13).

Serological studies, conducted in 2007-2008, show there is a statistically significant reduction in the risk of HBV among medical staff in Bulgaria $(\mathrm{p}<0.001)$ in comparison with the risk among the elderly population in the country: there was a smaller proportion of medical staff with acute HBV infection markers $-17.8 \%$, than the expected comparable age groups of the population $-27.5 \%$ in $1999-2000$, and $34-50 \%$ during the 1980 s $(2,4)$.

Despite these results, conducted seroepidemiological studies confirm that additional effort is required to achieve optimal protection of the medical staff, when it comes to the risk of HBV infections.

Based on medical staff protection factors established by those studies, there are approximately 36 500 non-vaccinated and nearly 30000 non-immune medical staff across all healthcare institutions in the country (3).

\section{AIM}

The aim of this study is to examine vaccination levels and other precautionary measures against blood-borne infections - HBV, HCV, HIV, and the attitude towards those among nurses at Dr Ivan Seliminski hospital - Sliven.

\section{MATERIALS AND METHODS}

An individual anonymous survey with 55 nurses, working in different wards of the hospital, was conducted in the period May-June 2016. The meth- ods used were: descriptive, statistical, graphic, and survey.

\section{RESULTS AND CONCLUSION}

Data from the survey shows that more than half of the respondents $-64 \%$, have more than 20 years of professional experience, whereas only $5 \%$ have less than 5 years (Fig. 1).

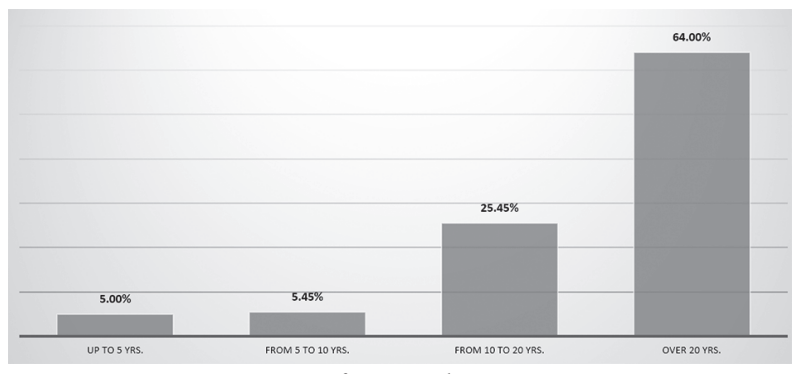

Fig. 1. Professional experience

The highest percentage of respondents work in high-risk wards - Surgery (16.36\%), Anaesthesiology and Intensive Care (9.09\%), Urology (7.27\%), Orthopaedics (9.27\%) and Maxillofacial Surgery (3.64\%). However, a significant number also work at therapeutic wards - Cardiology (12.73\%), Internal Diseases (9.09\%) (Fig. 2).

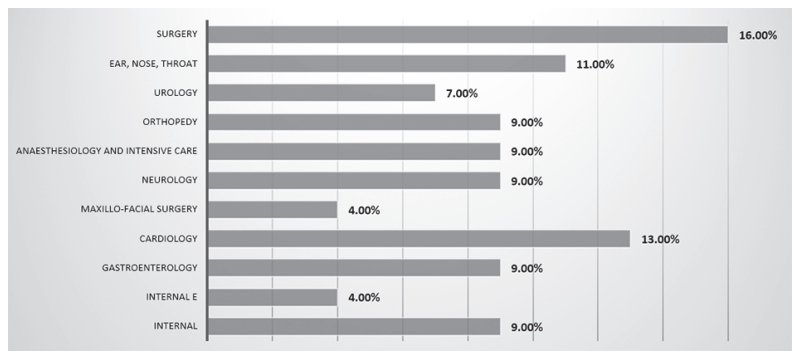

Fig. 2. Ward breakdown

More than half of the respondents $-64 \%$ have reported that they were always exposed to risk of $\mathrm{HBV}, \mathrm{HCV}$ and HIV infections during work and occupational healthcare. However, we have to note that there is a significant number who believed they were exposed to occupational risk of these infections only sometimes (Fig. 3). Nurses having longer professional experience were much more aware of the occupational risk of blood-borne infections. The highest percentage of respondents who understood they were 
always at risk at work had more than 20 years of service $-43.64 \%$ (Fig. 4).

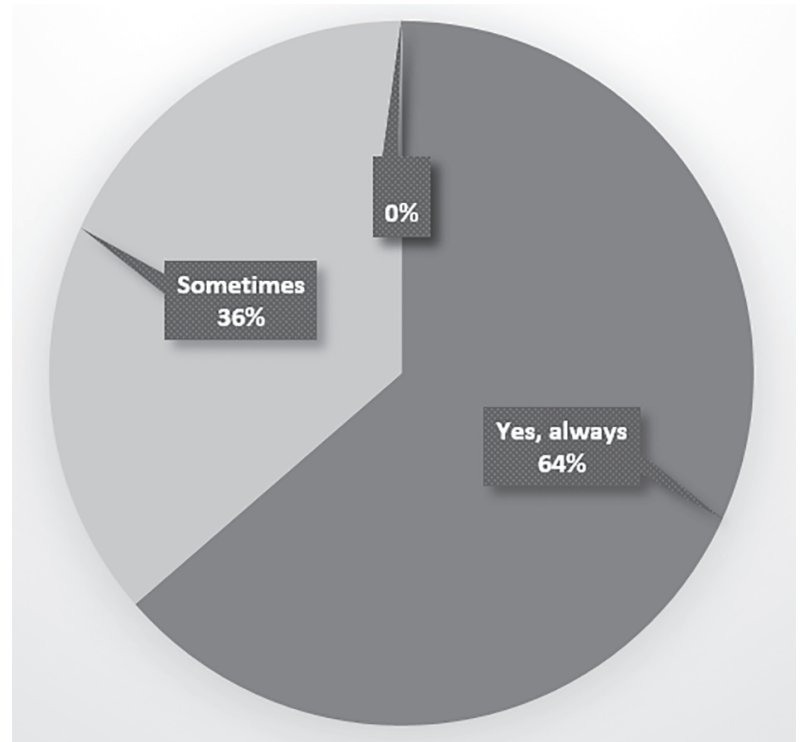

Fig. 3. Risk self-assessment

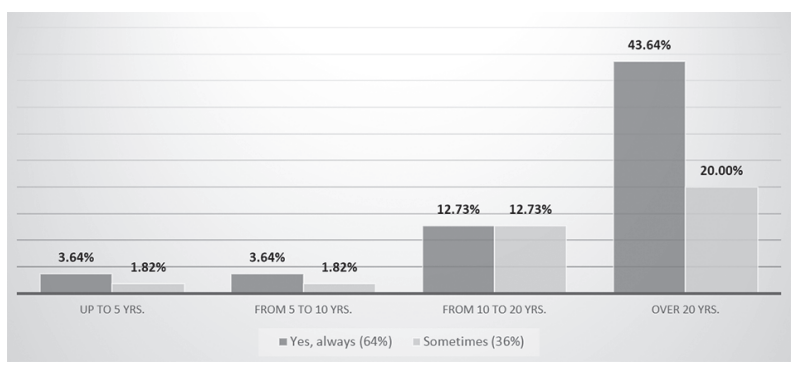

Fig. 4. Risk self-assessment and professional experience

According to studies conducted in a hospital in Dublin, Ireland, most nurses believe they have had HBV immunisations, however a significant number did not know the level of HBV antibodies (anti-HBs) (12).

Data from serological examination of staff at MHAT Stara Zagora in 2010 confirm there is a significant number of unprotected healthcare staff - prevalence of anti-HBs can be found only in $58.4 \pm 6.4 \%$ of the respondents (6).

Results from our study show that whilst more than half (58\%) have had serologic status testing for HBV, HCV and HIV, a significant number have not been tested $-42 \%$ (Fig. 5). More than half of the nurses $-68 \%$, indicated they have had immunisation and testing as a precautionary measure, $18 \%$ following exposure to infected patient's blood and $15 \%$ due to routine/requested medical screening (Fig. 6).

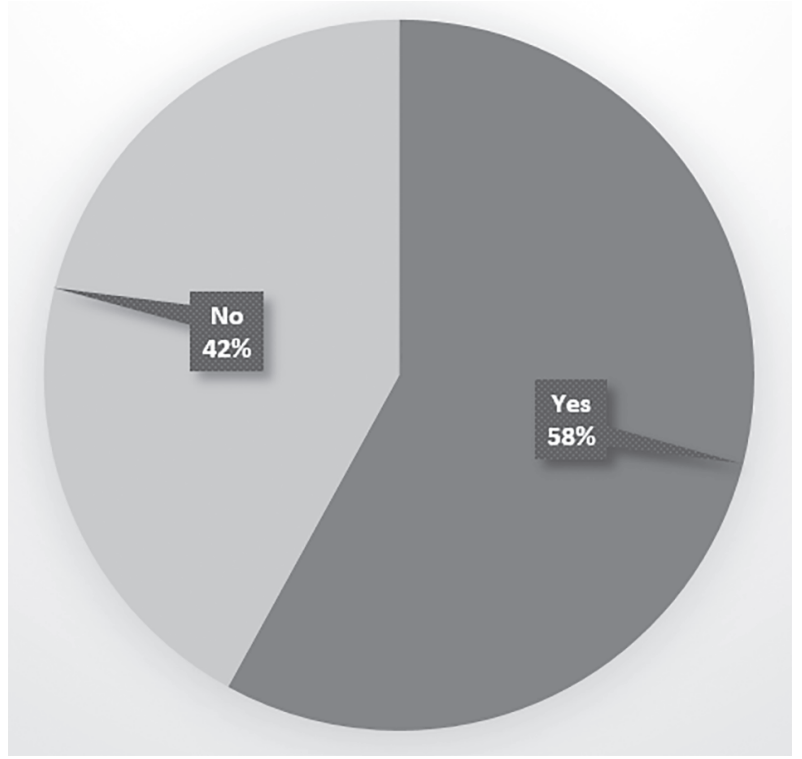

Fig. 5. Completed HBV, HCV and HIV testing

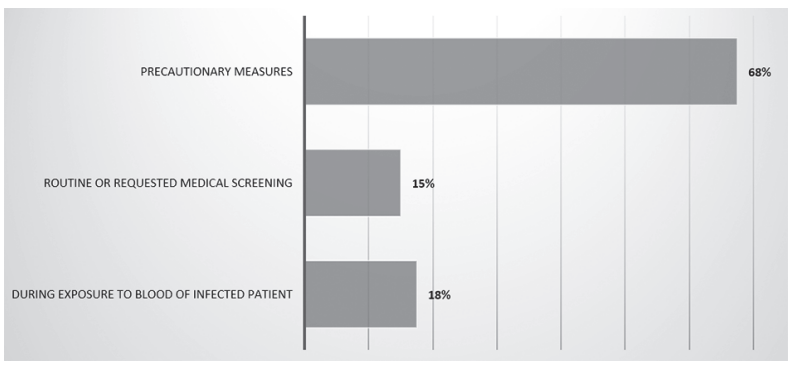

Fig. 6. Reasons for testing for $\mathrm{HBV}, \mathrm{HBC}$ and $\mathrm{HIV}$

According to recommendations, based on conducted studies, medical staff who falls into occupation groups with a higher risk of exposure to bloodborne infection agents must have post-infection or post-vaccine immunity against $\mathrm{HBV}$ (anti-HBs $>10$ $\mathrm{mIU} / \mathrm{ml}$ ), which is formally documented via laboratory examination (5).

Based on the Methodological Guidelines for the Protection of Medical Personnel from HIV, HBV and HCV infections, established with an official document RD 09-693 from 25.08.2004, there must be free provision of $\mathrm{HBV}$ vaccinations for medical staff with occupational risk. This should be applied following informed consent in accordance with Bulgaria's rules for immunisations (7). 
Pepa Dzhedzheva, Elena Zheleva, Ivan Alexandrov et al.

Medical personnel should undergo free HBV vaccination during their studies, or no later than the start of their occupational career. In Bulgaria, HBV vaccination of medical and non-medical professionals is applied in accordance with Ordinance 4/14.10.2002 for the protection of workers under occupational risk of exposure to biological agents and in accordance with Ordinance 15 from 2005 of the Ministry of Health for immunisations in Bulgaria (8).

Vaccine prophylaxis expenses for medical personnel are approximately ten times lower than those needed for the treatment of a potential infection (15).

Our survey shows that employers provide free vaccine in $76 \%$ of the cases, which is most common at high-risk wards, such as Surgery (Fig. 7).

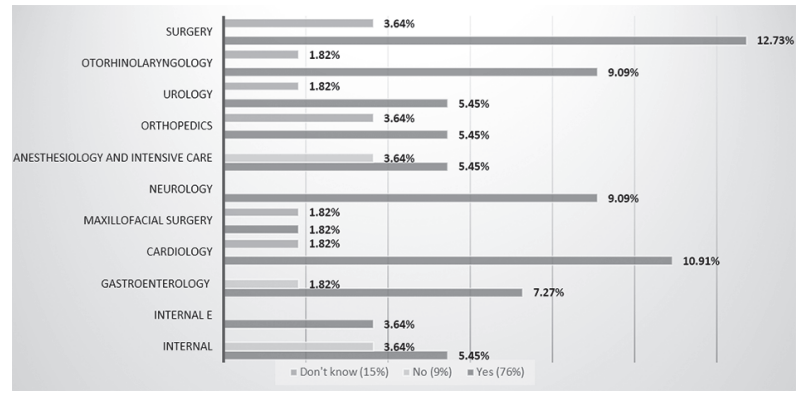

Fig. 7. Provision of free vaccines per wardhe

HBV vaccine is considered a very important preventive measure (14). The recombinant HBV vaccine has shown an excellent protective effect, good immunogenicity in different immunisation schemes and very good tolerance. The vaccine is significant for the purposes of mass-vaccination as well as for the vaccination of high-risk occupational groups. The application of a secure and safe vaccine can prevent the development of serious complications related to HBV infections $(11,17,18)$.

Results from the study show that a large proportion of the respondents have had an HBV vaccine - 71\%, with a still significant number of non-vaccinated nurses $-29 \%$ (Fig. 8). In order to achieve optimal prevention and protection it is required to monitor the vaccination of nurses on an annual basis.

During the identification of the nurses' attitudes towards the HBV vaccine, we have established that $64 \%$ of those who have not been vaccinated are

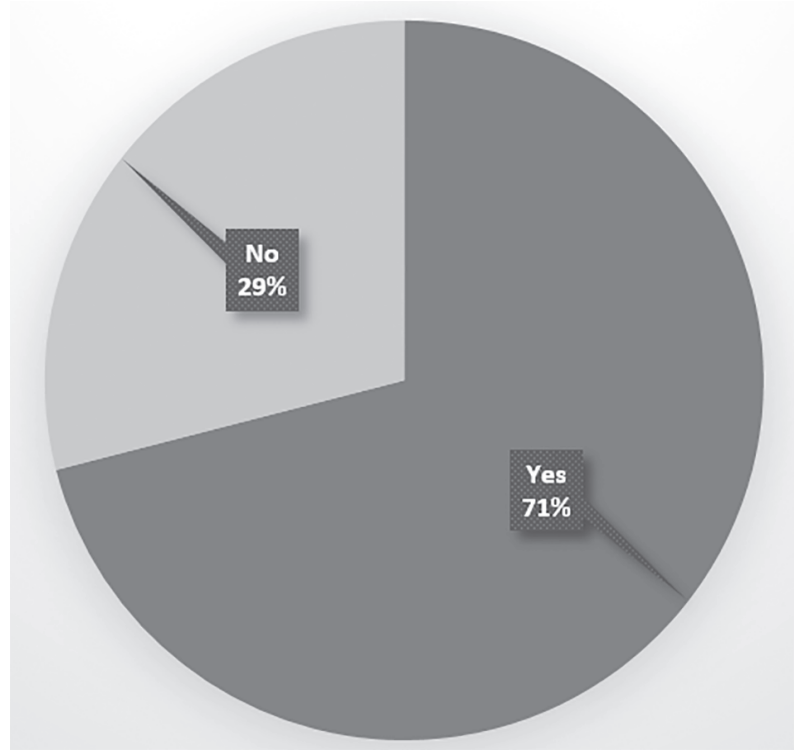

Fig. 8. HBV vaccines administered

afraid of the side effects of the vaccine. Twenty-one percent point out that they have not done it due to financial reasons, whilst 7\% do not trust the preventive action of the vaccine. Seven percent of the respondents have not had an HBV vaccine administered because they do not believe they are exposed to any risks (Fig. 9).

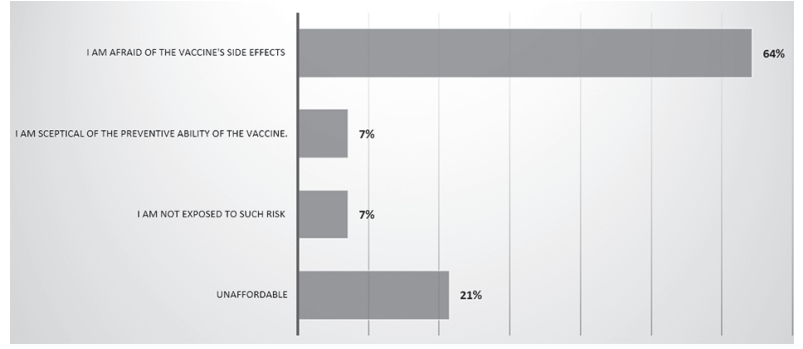

Fig. 9. Attitude to the HVB vaccine

Nurses' attitude towards the hepatitis vaccine can be altered via providing them with additional information about the benefits and risks of HBV immunisation.

\section{CONCLUSION}

In order to achieve maximum vaccine coverage among nurses it is required to:

$\diamond$ constantly provide staff with education about the risks of HBV infections and the need of the vaccine; 
Prevention of Blood-Borne Infections among Nurses at Dr. Ivan Seliminski Hospital, Sliven

$\diamond$ supply free vaccines to protect nurses against blood-borne infections as a regular part of every hospital's health and safety protocol;

$\diamond$ introduce serologic status testing as a pre-employment requirement for nurses or a requirement for acceptance in medical universities, as well as ensure that there is enough financial resource for hospitals and education establishments to conduct the testing and supply the $\mathrm{HBV}$ vaccine.

\section{REFERENCES}

1. Galev A. Vaksinite - predimstva i bezopastnost. Prevantivna medicina.2012; 1:4-5.

2. Gacheva N, Teoharov P, Ivanova R, Voinova-Georgieva $\mathrm{V}$. Razprostranenie na hepatit $\mathrm{B}$ i hepatit $\mathrm{C}$ infekci sred medicinskiya personal v Bulgaria: Multicentrovo seroepidemiologichno prouchvane, 2007 - 2008. Nozokomialni infekcii. 2008; 4 (1-2): 69-74.

3. Gacheva N, Voinova-Georgieva V, Vacheva-Dobrevska R, Teoharov P, et al.; Zashtita na medicinskia personal s hepatit B imunizacia: analiz na serologichni i epidemiologichni danni ot MBAL v stranata. Nozokomialni infekcii. 2010; 1-2; 53-57.

4. Gabev E. Virusni hepatiti. In: Kuzmov K, ed. Epidemiologia. Sofia: Medicina i fizkultura; 1988: 125-134.

5. Teoharov P, Gacheva N. Preporaki za proslediavnane na vaksinalnata zashtita sreshtu virusen hepatit B pri medicinski personal. Nozokomialni infekcii. 2009; 5 (1-2): 106-7.

6. Caneva V, Djeneva H, Lazarova G, Dobrev K, Ruseva S. Zashtita na personala na UMBAL Stara Zagora sreshtu virusen hepatit B: anketno prouchvane. Nozokomialni infekcii. 2010; 1-2: 58-62.

7. Metodichno ukazanie za predpazvane na medicinskia personal ot infekcia s HIV, hepatit $\mathrm{B}$ i $\mathrm{C}$ virus, utvurdeno sus Zapoved № RD 09-693/ 25.08.2004. Sl. Buletin. 2005;9.

8. Naredba 4/14.10.2002 za zashtitite na raboteshtite ot riskove, svurzani s ekspozicia na biologichni agenti pri rabota i v suotvestvie s Naredba № 15 na MZ ot 2005g. za imunizaciite v R. Bulgaria. Darzhaven vestnik. 2005; 45.

9. Beltrami EM, Williams IT, Shapiro CN, Chamberland ME. Risk and management of blood-borne infections in health care workers. Clin Microbiol Rev. 2000; 13(3):385-407.
10. Ganczak M, Ostrowski M, Szych Z, Korzen M. A complete HBV vaccination coverage among Polish surgical nurses in the light of anti-HBc prevalence: A cross-sectional sero-prevalence study. Vaccine. 2010; 28(23):3972-6.

11. Keating GM, Noble S. Recombinant hepatitis B vaccine (Engerix-B): a review of its immunogenicity and protective efficacy against hepatitis B. Drugs. 2003;63(10):1021-51.

12. McGrane J, Staines A. Nursing staff knowledge of the hepatitis B virus including attitudes and acceptance of hepatitis B vaccination: development of an effective program. AAOHN. 2003 Aug; 51(8):347-52.

13. Prüss-Üstün A, Rapiti E, Hutin Y. Sharps injuries. Global burden of disease from sharps injuries to health-care workers. Environmental Burden of Disease Series, No. 3. Geneva: World Health Organization, Protection of the Human Environment, 2003.

14. Rachiotis G, Goritsas C, Alikakou V, Ferti A, Roumeliotou A. Vaccination against hepatitis B virus in workers of a general hospital in Athens. Med Lav. 2005 Jan-Feb; 96(1):80-6.

15. Smith $S$, Weber S, Wiblin T et al. Costeffectiveness of hepatitis A vaccination in health care workers. Inf Control Hosp Epidemiol. 1997:688-692.

16. CDC. A comprehensive immunization strategy to eliminate transmission of hepatitis B virus infection in the United States: recommendations of the Advisory Committee on Immunization Practices. Part II: immunization of adults. MMWR. 2006; 55(16).

17. Immunization of Health-Care Workers: Recommendations of the Advisory Committee on Immunization Practices (ACIP) and the Hospital Infection Control Practices Advisory Committee (HICPAC). MMWR. 1997; 46(18):1-42.

18. Updated U.S. Public Health Service Guidelines for the Management of Occupational Exposures to $\mathrm{HBV}, \mathrm{HCV}$, and HIV and Recommendations for Postexposure Prophylaxis. MMWR Recomm Rep. 2001; 50(11): 1-42. 